\title{
An Unusual Type of Choledochal Cyst with Huge Dilation of Extrahepatic Bile Duct from Hilum to Ampulla of Vater; a Case Report and Literature Review
}

\author{
Adel Zeinalpour (iD ${ }^{1}$, Mehran Noori ${ }^{1}$ and Barmak Gholizadeh (iD ${ }^{*}$ \\ ${ }^{1}$ Department of General Surgery, Shahid Beheshti University of Medical Sciences, Tehran, Iran \\ "Corresponding author: Department of General Surgery, Shahid Beheshti University of Medical Sciences, Tehran, Iran. Email: barmak.gholizadeh@gmail.com
}

Received 2019 April 10; Revised 2019 July 08; Accepted 2019 July 10.

\begin{abstract}
Introduction: Choledochal cyst is a rare problem, defined as congenital dilatation of the biliary tract. There are five particular categories of choledochal cysts with some sub-types. The optimal management is removal of entire extrahepatic biliary system in addition to cholecystectomy and reconstruction by Roux-en-Y hepaticojejunostomy.

Case Presentation: We reported a 25 years old patient with a giant choledochal cyst. This Choledochal cyst may belong to subtype 1a plus affecting the intrapancreatic portion of common bile duct (CBD). The cyst was successfully resected without any complications. Conclusions: Intraoperative finding of choledochal cyst is very important, therefore, knowledge of potential presence of this rare disease and its management with respect to anatomical variations is very important for surgeons.
\end{abstract}

Keywords: Common Bile Duct, Choledochal Cyst, Case Reports

\section{Introduction}

Choledochal cysts are congenital anomalies of the biliary tract and defined as cystic distension of the biliary system. The incidence rate has been reported at 1:100,000 (1) and occurs more frequently in women (2). Seventy five percent of cysts are diagnosed in childhood and $25 \%$ in adulthood. Todani et al. described five main types of classification for choledochal cysts $(3,4)$. Type 1 is more prevalent and is seen in $80 \%$ of patients. This involves the dilatation of the whole common hepatic duct (CHD) or common bile duct (CBD) or some parts of them. It is categorized into three subtypes: subtype $1 \mathrm{~A}$ which is defined as dilatation of whole extrahepatic biliary system, subtype $1 \mathrm{~B}$ (segmental dilatation), and subtype $1 \mathrm{C}$ (dilatation of CBD alone). Type II is CBD diverticulum, type III is the choledochocele of intraduodenal portion of the CBD, type IV, is defined as several dilatations of the extrahepatic biliary system with or without intrahepatic involvement, and type $\mathrm{V}$ is defined as involvement of the intrahepatic biliary branches only. The pathophysiology of choledochal cysts remains unknown. One introduced hypothesis is anomalous pancreaticobiliary ductal convergence (4). The computed tomography scan (CT scan), magnetic resonance cholangiopancreatog- raphy (MRCP), and endoscopic retrograde cholangiography (ERC) are useful to diagnose and classification of the choledochal cysts. Surgeons use these modalities to select the best surgical intervention.

In adulthood, nonspecific abdominal pain is the most prevalent symptom. Abdominal mass or pain and jaundice are more common in children. Choledochal cysts can harbor malignant transformation with increased age (2). Historically, drainage procedures were used to treat choledochal cysts; but due to the risk of malignancy, optimal management is complete excision of the extrahepatic duct, cholecystectomy, and then reconstruction by roux-en-Y hepaticojejunostomy (5). Complete excision is the treatment choice for type I, II, and IVa cysts and endoscopic sphincterotomy is for choledochocele (type 3), which should be limited to the management of smaller lesions.

The prognosis is good and long term postoperative follow up is important to detect the complications (6).

In the present study, we presented our experience of a young man by a giant choledochal cyst who was successfully operated in our department. 


\section{Case Presentation}

A 25-year-old man was admitted to the surgical department of Shahid Modarres hospital. He had pruritus and had no drug or family history. His blood pressure was $110 / 70 \mathrm{mmHg}$, pulse rate was 73 beats/min, and temperature was $36.8^{\circ} \mathrm{C}$. With the exception of yellow skin, sclera, multiple abrasions in his body, and fullness in his right upper quadrant of abdomen, we did not detect any significant on physical examination.

The laboratory tests for white blood cells, hemoglobin, and platelets counts revealed $9.4 \times 10^{9} / \mathrm{L}, 9.9 \mathrm{~g} / \mathrm{dL}$, and 186 $\times 10^{9} / \mathrm{L}$, respectively. The blood levels of total and direct bilirubin were 9.27 , and $6.09 \mathrm{mg} / \mathrm{dL}$, respectively. Amylase levels was normal. Blood levels of alkaline phosphatase, aspartate aminotransferase, and alanine aminotransferase were 1166,120 , and $135 \mathrm{IU} / \mathrm{L}$, respectively.

Ultrasound imaging showed a large cyst which was $122 \times 120 \mathrm{~mm}$ with internal echo in liver bed. Report of magnetic resonance cholangiopancreatography (MRCP) revealed a $127 \times 120 \mathrm{~mm}$ cyst from hepatic bifurcation to ampulla of Vater (Figure 1).

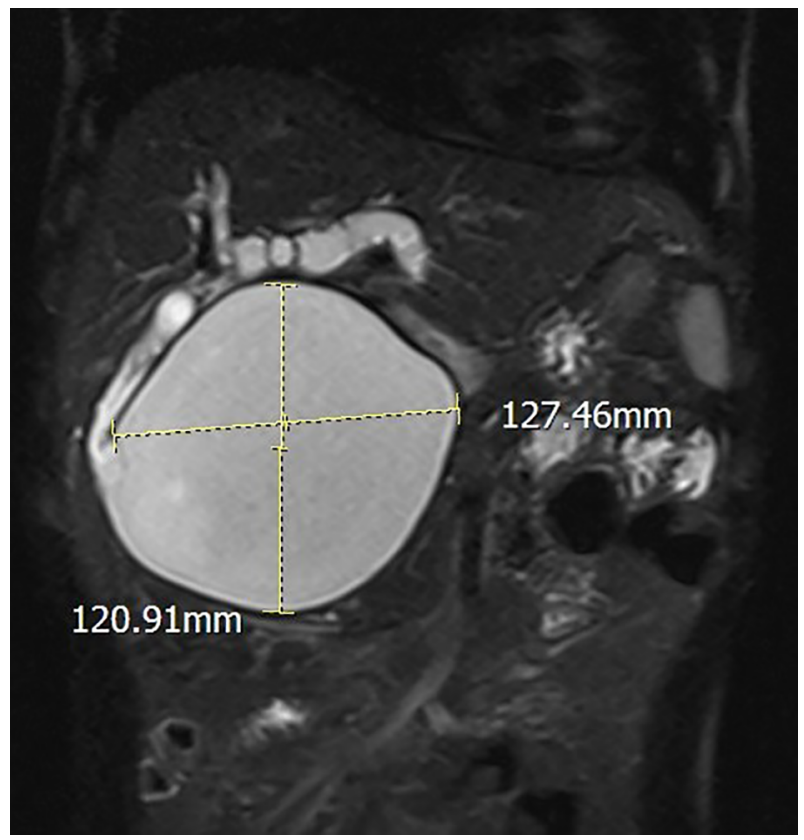

Figure 1. MRCP view of the giant choledochal cyst

The case was presented in the multidisciplinary team (MDT) and based on the recommendation he underwent an operation.

After general anesthesia, the abdomen was entered through the right subcostal incision. During exploration, we encountered a large cyst from the hilum of the liver to posterior wall of the duodenum. The cyst and gallbladder were freed from surrounding structures meticulously (Figure 2), and distal end of the cyst was ligated and divided. The posterior wall of the cyst was then carefully freed from the portal vein and hepatic artery and after dividing, the proximal end of the cyst was completely removed (Figure 3). To reconstruct the biliary flow, we used retro colic Roux-en-Y hepaticojejunostomy anastomosis using 4 - 0 absorbable interrupted stitches by $60 \mathrm{~cm}$ long roux limb. There was 100 cc bleeding during the operation and the operative time was about 180 minutes. Postoperative period was unremarkable and he discharged on forth-postoperative day. The pathologic report confirmed the diagnosis without malignancy and proximal and distal margins were clear. The patient did not complaint of any problem during the 6th month follow up visit.

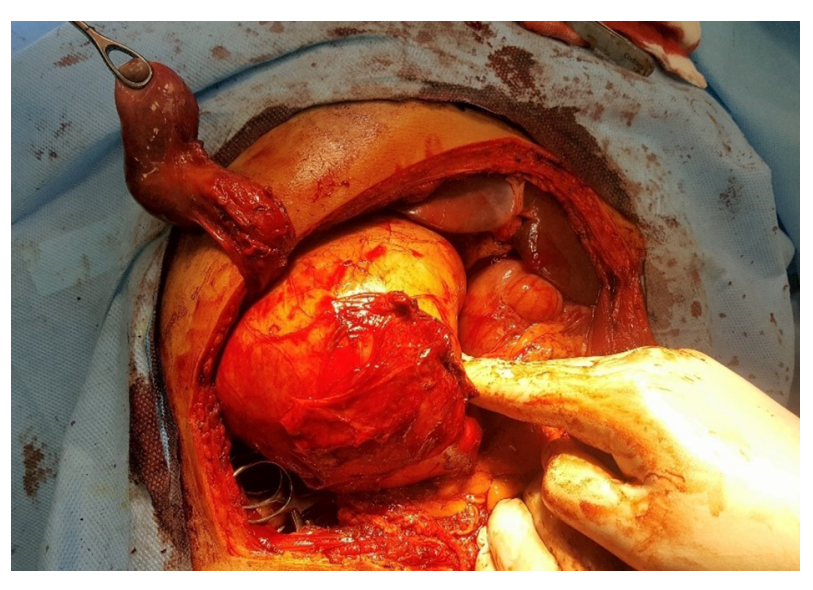

Figure 2. Intra operative view of the giant choledochal cyst

\section{Discussion}

Choledochal cyst is defined as the cystic expansion of extrahepatic bile ducts, which may be associated with the dilatation of the intrahepatic bile ducts or not (7). Type 1 is the most common type and type 1a defined as complete dilatation of completely extrahepatic portion of the biliary tree. The case of this study, was complete dilatation of CBD and CHD from confluence of the right and left hepatic ducts to ampulla of Vater, and included dilatation of intrapancreatic portion of biliary tract. The anatomy of the patient was not compatible with any of the known definitions of choledochal cysts. This dilatation was proceeded in the pancreas without affecting the pancreatic duct. This 


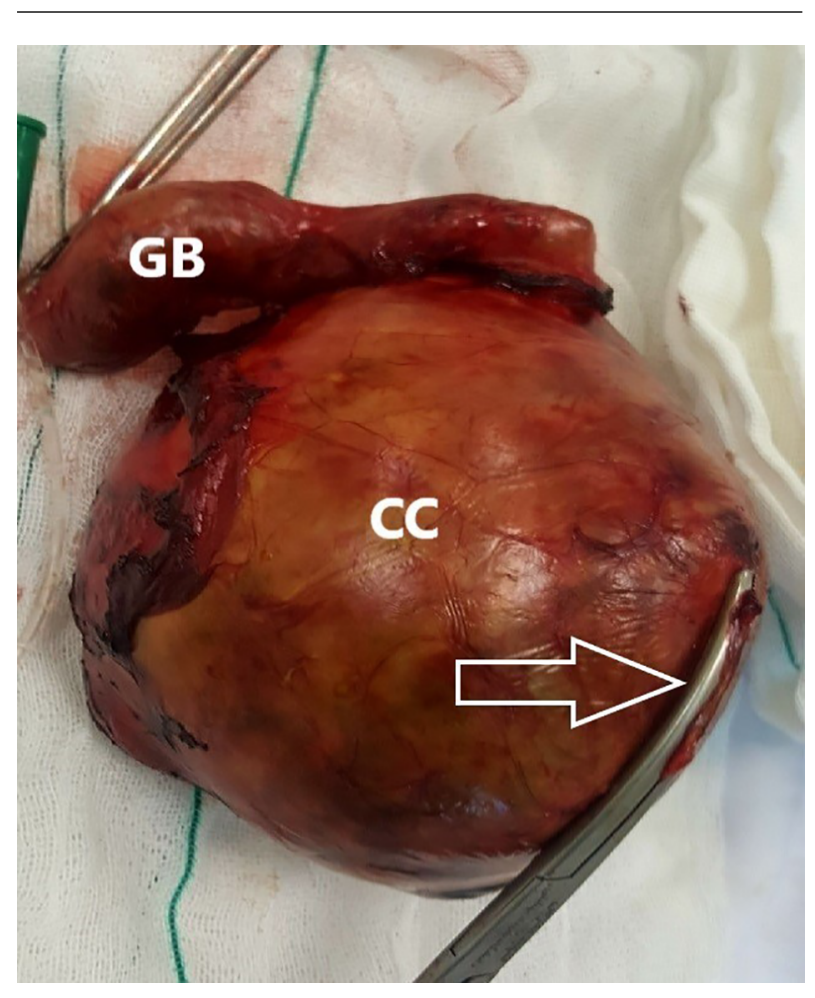

Figure 3. The resected choledochal cyst (CC) with the attached gallbladder (GB). The arrow indicates proximal end of the choledochal cyst.

choledochal cyst may belong to subtype 1a plus affecting the intrapancreatic portion of CBD. According to our literature review, finding of this size of dilation $(12 \mathrm{~cm})$ from hepatic hilum to ampulla of Vater is unique in choledochal cysts especially in an adult patient (8-10).

The treatment for choledochal cysts is surgical resection because these cysts can predispose malignancies mainly cholangiocarcinoma. The recommended procedure is complete removal of the cyst and reconstruction with Roux-en-Y hepaticojejunostomy (5). This procedure can be done in open and laparoscopic manner (11). Due to lack of data in adult choledochal cyst, the huge size of the cyst, and unique course of that in the patient through the head of the pancreas, recommendation of MDT was an open procedure. The procedure was very difficult and challenging especially dissection of cyst wall from duodenal wall and dissection of intrapancreatic portion of the cyst without damage to pancreatic duct. Fortunately, the resection and reconstruction were successfully done without any complication.

Choledochal cysts are more frequent in childhood but surgeons should consider the possibility in the differential diagnosis especially in younger adults with colicky right upper quadrant pain and jaundice. The surgeons should know about its diagnosis and management. Suboptimal surgery may cause remained cyst tissue and do not withhold the risk of future malignancy potential.

The accidental encounter of choledochal cysts may occur during surgery for any abdominal surgeon, so awareness of the possible presence of this uncommon disease and its management have paramount importance in education surgeons.

\section{Acknowledgments}

The authors would like to thank the operating room staff who helped us with the execution of this study.

\section{Footnotes}

Authors' Contribution: It is not declared by the authors. Conflict of Interests: There are no conflicts of interest. Funding/Support: It is not declared by the authors.

Patient Consent: The authors affirm that all appropriate patient consent forms have been taken. In the form, the patient accepted the report of his images and other clinical information without mentioning his name.

\section{References}

1. de Vries JS, de Vries S, Aronson DC, Bosman DK, Rauws EA, Bosma A, et al. Choledochal cysts: Age of presentation, symptoms, and late complications related to Todani's classification. J Pediatr Surg. 2002;37(11):1568-73. doi: 10.1053/jpsu.2002.36186. [PubMed: 12407541].

2. Liu YB, Wang JW, Devkota KR, Ji ZL, Li JT, Wang XA, et al. Congenital choledochal cysts in adults: Twenty-five-year experience. Chin Med J (Engl). 2007;120(16):1404-7. doi: 10.1097/00029330-20070802000005. [PubMed: 17825168].

3. Okada A, Higaki J, Nakamura T, Fukui Y, Kamata S. Pancreatitis associated with choledochal cyst and other anomalies in childhood. Br J Surg. 1995;82(6):829-32. doi: 10.1002/bjs.1800820635. [PubMed: 7627524].

4. Miyano T, Yamataka A, Kato Y, Segawa O, Lane G, Takamizawa S, et al. Hepaticoenterostomy after excision of choledochal cyst in children: A 30-year experience with 180 cases. J Pediatr Surg. 1996;31(10):1417-21. doi: 10.1016/s0022-3468(96)90843-x. [PubMed: 8906676].

5. Lee HK, Park SJ, Yi BH, Lee AL, Moon JH, Chang YW. Imaging features of adult choledochal cysts: A pictorial review. Korean J Radiol. 2009;10(1):71-80. doi: 10.3348/kjr.2009.10.1.71. [PubMed: 19182506]. [PubMed Central: PMC2647175].

6. Medina Lira AK, Mayorga Soto AJ, Frigerio P. Choledochal cyst Todani IA case report. Int J Surg Case Rep. 2016;28:293-5. doi: 10.1016/j.ijscr.2016.10.005. [PubMed: 27769027]. [PubMed Central: PMC5072142].

7. Metcalfe MS, Wemyss-Holden SA, Maddern GJ. Management dilemmas with choledochal cysts. Arch Surg. 2003;138(3):333-9. doi: 10.1001/archsurg.138.3.333. [PubMed: 12611583]. 
8. Shah OJ, Shera AH, Zargar SA, Shah P, Robbani I, Dhar S, et al. Choledochal cysts in children and adults with contrasting profiles: 11-year experience at a tertiary care center in Kashmir. World J Surg. 2009;33(11):2403-11. doi: 10.1007/s00268-009-0184-2. [PubMed: 19701664].

9. Woon CY, Tan YM, Oei CL, Chung AY, Chow PK, Ooi LL. Adult choledochal cysts: An audit of surgical management. ANZ J Surg. 2006;76(11):981-6. doi: 10.1111/j.1445-2197.2006.03915.x. [PubMed: 17054547].
10. Gadelhak N, Shehta A, Hamed H. Diagnosis and management of choledochal cyst: 20 years of single center experience. World J Gastroenterol.2014;20(22):7061-6. doi:10.3748/wjg.v20.i22.7061. [PubMed: 24944503]. [PubMed Central: PMC4051952].

11. Shen HJ, Xu M, Zhu HY, Yang C, Li F, Li KW, et al. Laparoscopic versus open surgery in children with choledochal cysts: A metaanalysis. Pediatr Surg Int. 2015;31(6):529-34. doi: 10.1007/s00383-0153705-0. [PubMed: 25895070]. 